\title{
Custo de produção de soja transgênica em sistema de semeadura direta em São Desidério-BA
}

\author{
Conrado Garcia Santos ${ }^{1}$, Gustavo Luís Mamoré Martins ${ }^{1}$, Pedro Augusto Silva ${ }^{2}$, Tiago Zoz ${ }^{1}$ \\ ${ }^{1}$ Universidade Estadual de Mato Grosso do Sul, Unidade Universitária de Cassilândia, Cassilândia, Mato Grosso do Sul, Brasil. \\ E-mail: conrado_garciasantos@hotmail.com,gustavomamore@yahoo.com.br,zoz@uems.br. \\ ${ }^{2}$ Grupo Iowa. São Desidério, Bahia, Brasil. E-mail: pedros@grupoiwoa.com.br
}

Recebido: 18/01/2017; Aceito: 08/06/2017

\section{RESUMO}

O objetivo do trabalho foi estimar o custo de produção da soja transgênica, em sistema de semeadura direta na região oeste do estado da Bahia. A pesquisa foi conduzida, na forma de estudo de caso, em uma propriedade rural localizada no município São Desidério (BA). Para levantamento do custo de produção utilizou-se a metodologia do sistema de Custo Operacional Total (COT). Os dados relativos aos coeficientes técnicos da cultura, utilizados no cálculo do custo de produção, foram levantados de uma planilha de controle administrativo, na safra 2015/2016. Foram calculadas médias e porcentagens de cada item do custo de produção de soja em um hectare. O Custo Operacional Total foi de R $\$ 2001,37 \mathrm{ha}^{-1}$, contribuindo com maior impacto os herbicidas $(33,82 \%)$ e adubos $(29,73 \%)$. A soja transgênica cultivada em sistema de semeadura direta alcançou menor custo do que outros sistemas de cultivo. A produção com métodos conservacionistas, como o plantio direto e a terceirização das operações agrícolas se revelaram importantes para diminuição de custos favorecendo maior rentabilidade da cultura.

Palavras-chave: Glycine max, plantio direto, terceirização, despesas.

\section{Production cost of transgenic soybean in no till system in São Desidério-BA}

\begin{abstract}
The objective of this study was to estimate the production cost of transgenic soybeans under no-till in the western region of the State of Bahia, Brazil. The research was conducted as a case study, in a rural farm located in the municipality of São Desidério (BA). The methodology of the Total Operating Cost (TOC) system was used to determine the cost of production. Data on the technical coefficients of the crop, used to calculate the cost of production, were taken from an administrative control sheet, in the 2015/2016 harvest. Averages and percentages of each item of soybean production cost were calculated for one hectare. The TOC was R $\$ 2,001.37$ per hectare, with a greater impact on herbicides $(33.82 \%)$ and fertilizers $(29.73 \%)$. Transgenic soybean cultivated under no-till has a lower cost than in other cropping systems. Production with conservation methods, such as no-tillage, and the outsourcing of agricultural operations are important to reduce costs, which may favor higher crop yields.
\end{abstract}

Key words: Glycine max, no-till, outsourcing, expenses. 


\section{Introdução}

A estimativa da área cultivada com soja no Brasil na safra 2016 é de 33.207.270,00 de hectares, com uma produção de $96.026 .383,00$ toneladas. $\mathrm{Na}$ região nordeste, destaca-se o estado da Bahia, possuidor de uma área plantada de 1.527.000,00 hectares e produção de 3.212.600,00 toneladas, na safra 2016 (IBGE, 2017).

As cultivares transgênicas são utilizadas no sistema de produção de soja e possuem como vantagens a tolerância a lagartas e ao herbicida glifosato (MENEGATTI; BARROS, 2007; VILELA et al., 2016). A tolerância ao glifosato é proporcionada pela tecnologia Roundup Ready (RR). A proteção contra as lagartas é conferida por uma proteína Bt (Cry1Ac) que possui alta eficácia contra a lagarta da soja (Anticarsia gemmatalis), a lagarta falsa medideira (Chrysodeixis includens e Rachiplusia nu), a broca das axilas (Crocidosema aporema), a lagarta das maçãs (Heliothis virescens), elasmo (Elasmopalpus lignosellus) e Helicoverpa (H. zea e H. armigera) (JAMES, 2014).

Nos últimos anos, tem se observado uma grande expansão da área cultivada com soja transgênica, principalmente em sistema de semeadura direta. A semeadura direta ou plantio direto é uma prática conservacionista do solo, que substituiu processos mecânicos de preparo do solo, como a aração e gradagem, por práticas biológicas. A matéria orgânica sobre a superfície e o não revolvimento do solo em toda extensão e profundidade resultam em um solo estruturado (CASTRO et al., 2006; SIQUEIRA NETO et al., 2009). A utilização da semeadura direta, com revolvimento do solo somente na linha de semeadura, permite conservar resíduos na superfície do solo, proporcionando proteção contra o impacto direto da gota da chuva, reduzindo os riscos de perda de solo por erosão hídrica e auxiliando no controle de plantas daninhas (CUNHA et al., 2011; MELO et al., 2013).

O sistema de produção de soja transgênica em semeadura direta, assim como outros modos de cultivo, está sujeito a riscos, tanto biológicos como de mercado, que influenciam tanto na produtividade como no custo de produção e consequentemente na receita adquirida com a produção. A margem de lucro do produtor vai depender das condições edafoclimáticas da região, do nível tecnológico empregado e da capacidade de gerenciamento do produtor (ESPERANCINI et al., 2004; RICHETTI, 2015).

Entre as várias ferramentas de gestão disponíveis para subsidiar o planejamento produtivo destaca-se o custo de produção (MARTIN et al., 1998). O uso dessa ferramenta é imprescindível para verificar o custo e a receita realizada com a produção, identificando e eliminando as possíveis causas de redução de produtividade. Despesas com mão-de-obra, insumos, operações agrícolas, terceirização e outras despesas utilizadas em um processo produtivo, constituem o custo de produção, ou seja, os custos fixos e variáveis (RICHETTI, 2012).

O custo fixo remunera os fatores de produção cujas quantidades não alteram em curto prazo, mesmo tendo indicativos de mercado para mudar a escala de produção. Determina-se como custo fixo a depreciação e juros sobre o valor de máquinas e equipamentos e a remuneração do capital empregado em terra (estimada como valor de arrendamento). O custo variável considera as despesas realizadas com a produção, cujas quantidades podem ser modificadas em função do nível de produção desejada, como: sementes, fertilizantes, calcário, defensivos, mão-de-obra, combustíveis, lubrificantes, reparos de máquinas e equipamentos (MARTIN et al., 1998; GODINHO et al., 2006; RICHETTI, 2007).

Dessa forma, o custo de produção é composto por uma estrutura dividida em custo operacional efetivo (COE), composto por operações mecanizadas e insumos; e custo operacional total (COT), que se acrescenta ao $\mathrm{COE}$ os custos com encargos financeiros (juros de custeio) e outras despesas (VILELA et al., 2016).

Atualmente existem poucas informações disponíveis sobre o custo de produção nas áreas cultivadas de soja transgênica, onde há ausência da aração e gradagem, e terceirização das operações mecanizadas.

Desse modo, o objetivo do trabalho foi estimar o custo de produção da soja transgênica, em sistema de semeadura direta, em São Desidério (BA).

\section{Material e Métodos}

A pesquisa foi conduzida, na forma de estudo de caso, em uma propriedade rural localizada no município de São Desidério (BA), cujas coordenadas são latitude $13^{\circ} 04 \mathrm{~S}$ e longitude $45^{\circ} 56^{\prime} \mathrm{W}$ com uma altitude de 835 metros. O clima da região é classificado segundo Koppen como do tipo Aw.

O sistema de produção adotado foi o sistema de semeadura direta. Na área não foi utilizada aração e gradagem. O revolvimento do solo ocorreu somente na linha de semeadura. Para semeadura foi utilizada a cultivar de soja transgênica M8210 IPRO.

A pesquisa foi realizada no período de 02/11/2015 a 28/04/2016 período esse que se iniciaram e encerraram respectivamente os manejos relacionados ao cultivo da oleaginosa na propriedade. Os dados de custos inerentes do processo produtivo foram obtidos formalmente junto ao agrônomo responsável pela condução do empreendimento.

Para levantamento do custo de produção utilizou-se a metodologia do sistema de Custo Operacional Total (COT) também utilizada pelo Instituto de Economia 
Agrícola (IEA) e proposta por Matsunaga et al. (1976) com algumas adaptações ao estudo de caso.

Os dados relativos aos coeficientes técnicos da cultura, utilizados no cálculo dos custos de produção, foram levantados de uma planilha de controle administrativo do gerente da propriedade e dividida em etapas.

A primeira etapa constitui as operações mecanizadas, terceirizadas, englobando distribuição de calcário, semeadura e adubação, pulverizações terrestre e aérea e colheita. Os custos horários dessas operações foram obtidos do valor de serviço da empresa que terceiriza as operações das máquinas, na região, onde gastos com operador e depreciação de máquinas e implementos estão inclusos no valor pago pelo serviço. O conjunto Silo bolsa (com motor) foi utilizado para o armazenamento dos grãos na propriedade.

A segunda etapa está relacionada aos insumos utilizados na semeadura no processo de tratamento de semente. Posteriormente, na terceira etapa temos os insumos gerais que constituem os custos com correções da fertilidade do solo, manejo de plantas daninhas, pragas, doenças e fertilizações foliares. Na quarta etapa; gastos com mão-de-obra, que neste caso foi constituído por dois funcionários.

A somatória das despesas com as etapas anteriores constituiu-se o Custo Operacional Efetivo (COE). Sobre o valor do COE, foram acrescidas as taxas com juros de custeio $(6,75 \%$ de $50 \%$ do valor do COE) e outras despesas $(5,00 \%$ do valor total do COE). O Custo Operacional Total (COT) foi obtido pela somatória do COE, juros de custeio e outras despesas, sendo as taxas calculadas conforme Martin et al. (1998).

Os preços dos insumos e dos produtos referem-se aos preços pagos pelos produtores na região em novembro de 2016.

Foram calculadas médias e porcentagens de cada item do custo de produção de soja em um hectare, com o programa Microsoft Excel ${ }^{\circledR}$.

\section{Resultados e Discussão}

A estimativa do custo operacional total por $\mathrm{ha}^{-1} \mathrm{de}$ soja transgênica, em sistema de semeadura direta, em São Desidério-BA é mostrada na Tabela 1. Nas operações mecanizadas, o menor custo foi com o conjunto silo bolsa (com motor) ( $\mathrm{R} \$ 28,50)$ utilizado no armazenamento de grãos na propriedade. Observou-se maior custo com a pulverização terrestre e aérea $(\mathrm{R} \$$ 432,00).

As pulverizações foram realizadas por uma empresa terceirizada para o controle de pragas, doenças e plantas daninhas $\mathrm{O}$ maior custo com as pulverizações, nas operações mecanizadas (Tabela 1) também foi observado em lavouras de soja não transgênicas e que utilizam equipamentos próprios (não terceirizados). Castro et al. (2005) estimando o custo de produção de soja convencional, cultivada sob sistema de semeadura direta, no Oeste da Bahia, utilizando equipamentos próprios, observaram que os itens de maior participação no custo com máquinas e equipamentos foram representados pelos pulverizadores motorizados $\mathrm{e}$ tratores.

Em relação à colheita foi utilizado o serviço terceirizado, no valor de 2,20 sacas ha ${ }^{-1}$, com o preço da saca de $\mathrm{R} \$ 71,50$ e valor total de $\mathrm{R} \$ 157,30$ (Tabela 1). Durante o período de um ano, uma máquina que colhe soja trabalha aproximadamente 300 horas, com alto custo da hora-máquina. Após a safra, estes implementos ficam parados e sem uso na propriedade. Saída viável é a contratação de empresas terceirizadas, diminuindo o custo da hora-máquina e economizando um alto valor na aquisição de máquinas (APROSOJA, 2017). Desta forma, a adoção da terceirização das operações mecanizadas, no cultivo de soja transgênica em sistema de semeadura direta, é uma opção viável ao sojicultor.

Quanto aos insumos utilizados no tratamento de sementes, o maior custo observou-se na aquisição da semente transgênica (R\$219,00) (Tabela 1). Dentre todos os insumos geralmente utilizados; calcário, MAP (10-50$00), \mathrm{KCl}$, herbicidas, fungicidas, inseticidas, adjuvantes e fertilizantes foliares, o processo de dessecação foi o de maior custo. Neste caso o herbicida mais oneroso foi o Glifosate Potássico, totalizando um custo de R \$ 148,98 $\mathrm{ha}^{-1}$ (Tabela 1). Castro et al. (2005) obtiveram um custo menor, dentre os gastos com produtos químicos $(11,60 \%$ do custo final); os herbicidas representam $5,42 \%$ dentre os gastos com defensivos.

Quanto à mão-de-obra empregada na produção da soja, obteve-se um custo de R \$ 3,44 nessa propriedade. Foi obtido R\$ 62,33 com os juros de custeio (Tabela 1), considerando-se uma taxa de $6,75 \%$ ao ano, sobre metade do valor do custo operacional efetivo (COE).

O custo operacional total de produção de soja transgênica, em sistema de semeadura direta foi de R\$ 2001,37 (Tabela 1). Esse custo é 21,23\% menor do que os estimados por Vilela et al. (2016), utilizando a mesma metodologia desse trabalho, no custo de produção de soja em sistema de preparo do solo convencional na região de Chapadão do Sul, MS.

Relativamente às porcentagens das operações que compõe o custo de produção, as pulverizações terrestres e aéreas representam $59,81 \%$ e a colheita $21,78 \%$, ambas com a maior representatividade no custo com operações mecanizadas (Figura 1). Vilela et al. (2016) na região dos chapadões, observaram um custo com pulverizações de $44,06 \%$ do total dos gastos dentro das operações mecanizadas, $15,75 \%$ menor que do presente estudo, e com a colheita os custos foram semelhantes com uma pequena variação $(1,02 \%)$. 
Tabela 1. Estimativa do custo operacional total $\mathrm{ha}^{-1}$ de soja transgênica, em sistema de semeadura direta, em São Desidério-BA.

\begin{tabular}{|c|c|c|c|c|}
\hline Descrição & Esp. & C.T & V.U (R\$) & V.T (R\$) \\
\hline \multicolumn{5}{|l|}{ A. Operações mecanizadas } \\
\hline Distribuição de calcário (Terceirizado) & $\mathrm{R} \$ \mathrm{ha}^{-1}$ & 1,00 & 66,00 & 66,00 \\
\hline Semeadura e adubação (Terceirizado) & $\mathrm{R} \$ \mathrm{ha}^{-1}$ & 1,00 & 67,00 & 67,00 \\
\hline Pulverizações terrestre e aérea (Terceirizado) & $\mathrm{R} \$ \mathrm{ha}^{-1}$ & 8,00 & 54,00 & 432,00 \\
\hline Colheita (Terceirizado) & Sacas ha ${ }^{-1}$ & 2,20 & 71,50 & 157,30 \\
\hline Conjunto Silo bolsa (com motor) & Sacas ha ${ }^{-1}$ & 57,00 & 0,50 & 28,50 \\
\hline Subtotal A & & & & 750,80 \\
\hline B. Insumos-Semeadura & Esp. & 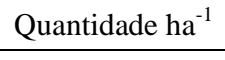 & V. U (R\$) & V. T (R\$) \\
\hline Semente & $\mathrm{Kg}$ & 31,39 & 6,98 & 219,10 \\
\hline Grafite & $\mathrm{Kg}$ & 0,42 & 1,74 & 0,73 \\
\hline Inoculante & $\mathrm{L}$ & 0,15 & 3,50 & 0,53 \\
\hline Tratamento de semente (Fipronil) & $\mathrm{L}$ & 0,03 & 115,96 & 3,94 \\
\hline Tratamento de semente (Tiametoxam) & $\mathrm{L}$ & 0,07 & 137,24 & 9,47 \\
\hline Tratamento de semente (Fludioxonil) & $\mathrm{L}$ & 0,03 & 137,24 & 4,67 \\
\hline Subtotal B & & & & 238,44 \\
\hline C. Insumos gerais & Esp. & Quantidade ha $^{-1}$ & V. U (R\$) & V. T (R\$) \\
\hline Calcário & Ton & 0,85 & 130,00 & 110,50 \\
\hline MAP (10-50-00) & $\mathrm{Kg}$ & 109,99 & 1,14 & 124,95 \\
\hline KCL & $\mathrm{Kg}$ & 149,99 & 0,86 & 128,99 \\
\hline Hercicida (S-Metolacloro) & $\mathrm{L}$ & 1,01 & 17,80 & 17,98 \\
\hline Herbicida (Clorimuron) & $\mathrm{Kg}$ & 0,03 & 29,06 & 0,99 \\
\hline Herbicida (Cletodim) & $\mathrm{L}$ & 0,95 & 120,00 & 114,00 \\
\hline Herbicida (Glifosato Potássico) & $\mathrm{L}$ & 5,53 & 26,94 & 148,98 \\
\hline Herbicida (Imazetapir) & $\mathrm{L}$ & 0,27 & 3,82 & 1,02 \\
\hline Herbicida (Paraquat) & $\mathrm{L}$ & 0,59 & 10,00 & 5,90 \\
\hline Fungicida (Trifloxistrobina+Protioconazol) & $\mathrm{L}$ & 0,40 & 100,00 & 40,00 \\
\hline Fungicida (Benzovindiflupir+Azoxistrobina) & $\mathrm{L}$ & 0,19 & 273,78 & 51,74 \\
\hline Inseticida (Acefato) & $\mathrm{Kg}$ & 0,84 & 33,90 & 28,54 \\
\hline Inseticida (Lambdacyhalotrin) & $\mathrm{L}$ & 0,01 & 153,07 & 1,06 \\
\hline Inseticida (Triflumurom) & $\mathrm{L}$ & 0,02 & 37,85 & 0,86 \\
\hline Inseticida (Clorpirifós) & $\mathrm{L}$ & 0,03 & 2,38 & 0,08 \\
\hline Inseticida (Lufenuron) & $\mathrm{L}$ & 0,01 & 16,30 & 0,09 \\
\hline Inseticida (Clorantraniliprole) & $\mathrm{L}$ & 0,01 & 57,58 & 0,65 \\
\hline Inseticida (Metomil) & $\mathrm{L}$ & 0,83 & 17,28 & 14,29 \\
\hline Inseticida (Flubendiamida) & $\mathrm{L}$ & 0,03 & 344,40 & 8,61 \\
\hline Inseticida (Imidacloprido+Beta-Ciflutrina) & $\mathrm{L}$ & 0,69 & 24,00 & 16,56 \\
\hline Adjuvante (Óleo Mineral) & $\mathrm{L}$ & 1,38 & 19,19 & 26,48 \\
\hline Adjuvante (Óleo Vegetal) & $\mathrm{L}$ & 0,11 & 26,66 & 2,83 \\
\hline Adjuvante (Éster Metílico) & $\mathrm{L}$ & 0,35 & 6,40 & 2,23 \\
\hline Fertilizante foliar Complexo de Bagual & $\mathrm{Kg}$ & 1,03 & 5,46 & 5,61 \\
\hline Fertilizante foliar Nitro 22 & $\mathrm{Kg}$ & 0,08 & 13,76 & 1,10 \\
\hline Subtotal C & & & & 854,03 \\
\hline D. Mão-de-obra & $\mathrm{R} \$ \mathrm{ha}^{-1}$ & 1,00 & 3,44 & 3,44 \\
\hline Custo Operacional Efetivo (COE) & & & & 1846,71 \\
\hline Juros de custeio $(6,75 \%)$ & & & & 62,33 \\
\hline Outras despesas $(5,00 \%)$ & & & & 92,34 \\
\hline Custo Operacional Total (COT) & & & & 2001,37 \\
\hline
\end{tabular}

* Esp: Especificação; C.T: Coeficiente Técnico; V.U: Valor Unitário; V.T: Valor Total. 
Na etapa da colheita, Richetti (2015) estudando a viabilidade econômica da cultura da soja na safra 2015/2016, em Dourados Mato Grosso do Sul, observou um custo de 15,3\%; valor inferior ao encontrado no presente trabalho $(21,78 \%)$ (Figura 1$)$. As diferenças entre estes valores devem-se por conta dos serviços mecanizados; no presente trabalho constatou-se o serviço terceirizado e naquele mão-de-obra própria.

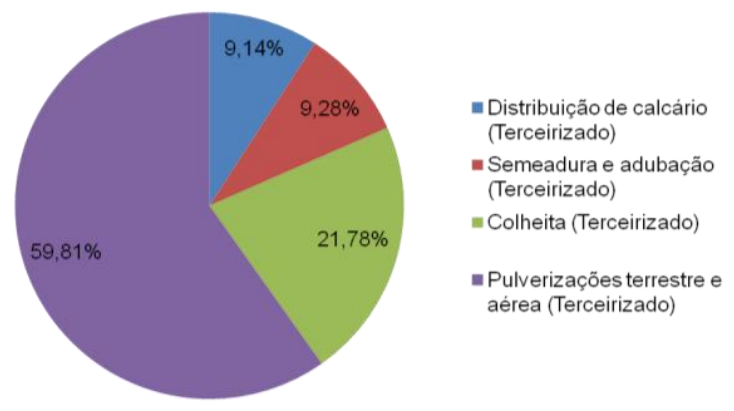

Figura 1. Porcentagem de cada item na operação mecanizada. São Desidério - BA. 2016.

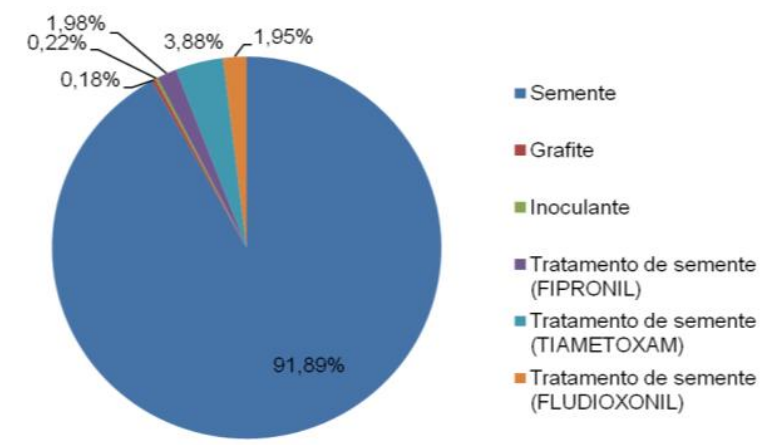

Figura 2. Porcentagem de cada item dos insumos da semeadura. São Desidério - BA. 2016.

Referente aos custos com insumos de semeadura, a semente transgênica representa 91,89\% (Figura 2). Este valor é próximo ao encontrado por Richetti (2015), que ao estudar o custo da soja na região de Dourados-MS, observou gastos com semente ( $\mathrm{R} \$ 325,00)$, tratamento de semente ( $\mathrm{R} \$ 37,61)$, inoculante $(\mathrm{R} \$ 2,50)$, gerando um montante de $\mathrm{R} \$ 365,11$, concluindo que os gastos com semente equivalem a $89 \%$ do custo total.

Dentre os insumos gerais destacam-se com maior impacto os herbicidas com $33,82 \%$ seguido por adubos $29,73 \%$ (Figura 3). Esses resultados diferem dos resultados encontrados por Richetti (2015), que ao estudar a viabilidade econômica da cultura da soja na região de Dourados-MS, utilizando a metodologia da Embrapa no levantamento de custos, obteve gastos com fertilizantes de $63 \%$ e com herbicidas de $13 \%$. Essas diferenças são devido à metodologia de levantamento de custos. No presente trabalho não foi incluída a depreciação de máquinas e implementos utilizados na aplicação de fertilizantes e herbicidas.
Insumos gerais representaram 42,67\% do custo operacional total (COT) (Figura 4), valor menor ao encontrado por Richetti (2015) em estudo onde os insumos representaram $50,4 \%$ do custo total da produção de soja na região de Dourados-MS. A diferença de valores pode ser consequência do preço praticado no comércio dos insumos nas regiões em que foram realizados os experimentos, visto que foram executados em locais e safras diferentes.

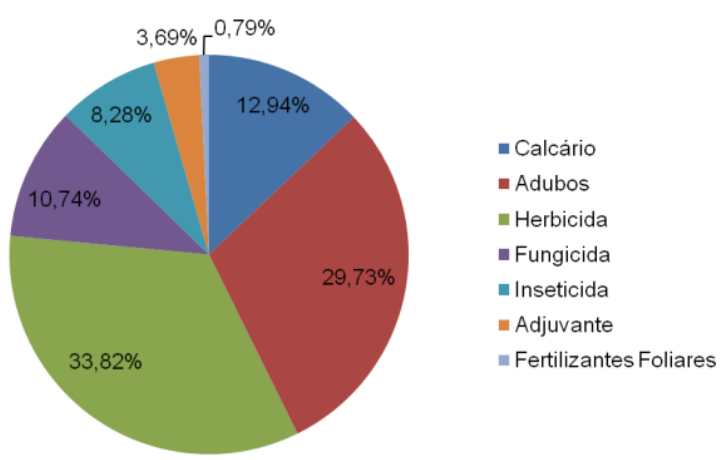

Figura 3. Porcentagem de cada item dos insumos gerais. São Desidério - BA. 2016.

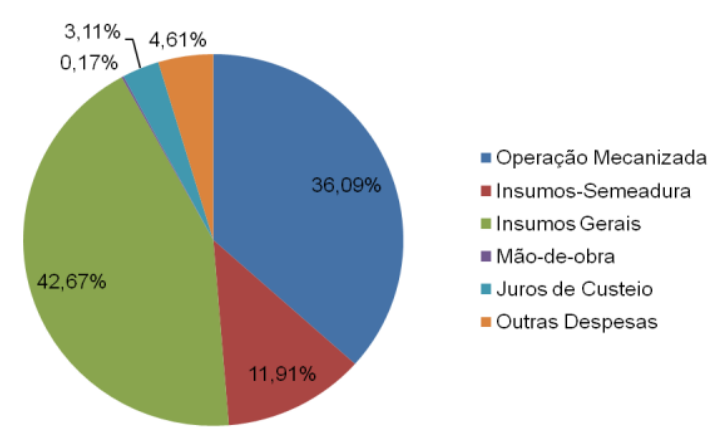

Figura 4. Porcentagem de cada item do custo operacional total (COT). São Desidério - BA. 2016.

Pelos resultados obtidos no presente estudo, verificase que o custo da soja transgênica, em sistema de semeadura direta, em São Desidério-BA, é menor do que em outras regiões, que normalmente empregam equipamentos próprios do produtor, como plantadeiras, tratores, pulverizadores e máquinas de colheita (VILELA et al., 2016).

Desse modo, a terceirização das operações mecanizadas (Tabela 1; Figura 4) mostrou-se importante a fim de reduzir custos no sistema de produção de soja, excluindo dos gastos a compra de implementos agrícolas e gastos relativos à depreciação do maquinário.

O sistema de semeadura direta (plantio direto), com ausência do preparo do solo, sem uso de aração e gradagem (Tabela 1) contribui para diminuir o custo de produção da soja, quando comparado ao sistema convencional (CASTRO et al., 2006). Além disso, o 
plantio direto é uma prática conservacionista de manejo do solo (MELO JUNIOR et al., 2011). Pelo contrário, a soja cultivada em sistemas convencionais e com o preparo intensivo do solo, além de degradar o solo, aumenta os custos com implementos agrícolas e gera uma menor margem de lucro da atividade (OLIVEIRA et al., 2013).

\section{Conclusões}

A soja transgênica cultivada em sistema de semeadura direta, em São Desidério (BA) obteve menor custo do que em outros sistemas de cultivo.

A produção com métodos conservacionistas, como o plantio direto, e a terceirização das operações agrícolas são importantes para diminuir custos e favorecer a maior rentabilidade da cultura.

\section{Referências Bibliográficas}

APROSOJA. ASSOCIAÇÃO DOS PRODUTORES DE SOJA E MILHO DE MATO GROSSO. Terceirização aumenta a competitividade da agricultura. Cuiabá-MT: APROSOJA, 2017. Disponível em http://www.aprosoja.com.br/comunicacao/release/terceirizaca o-aumenta-a-competitividade-da-agricultura. Acesso em: 15 jan. 2017.

CASTRO, S. H.; REIS, R.P.; LIMA, A. L.R. Custos de produção da soja cultivada sob sistema de plantio direto: estudo de multicasos no oeste da Bahia. Ciência e Agrotecnologia, Lavras-MG, v. 30, n. 6, p. 1146-1153, 2006.

CUNHA, E. Q.; STONE, L. F.; FERREIRA, E. P. B.; DIDONET, A. D.; MOREIRA, J. A. A.; LEANDRO, W. M. Sistemas de preparo do solo e culturas de cobertura na produção orgânica de feijão e milho. I - Atributos físicos do solo. Revista Brasileira de Ciência do Solo, Viçosa-MG, v. 35, n. 2, p. 603-611, 2011.

ESPERANCINI, M. S. T.; PAES, A. R.; BICUDO, S. J. Análise de rentabilidade e risco na produção de milho verão, em três sistemas de produtivos, na região de Botucatu, estado de São Paulo. Informações Econômicas, São Paulo-SP, v. 34, n. 1, p. 25-33, 2004.

GUERRA, R. R.; DORR, A. C.; COSTA, M. L.; FREITAS, C. A. A efetividade e a razão ótima de "hedge" para a soja na praça de Tupanciretã. Indicadores Econômicos, Porto Alegre-RS, v. 40, n. 2, p. 139-150, 2013.

GODINHO, V. P. C.; UTUMI, M. M.; LIVEIRA, S. J. M.; BROGIN, R. L.; RAMALHO, A. R. Estimativa de custos de produção de milho na região do cerrado de Rondônia, safrinha 2006. Porto Velho-RO: Embrapa Rondônia, 2006. 4 p. (Comunicado Técnico, 312).

IBGE. INSTITUTO BRASILEIRO DE GEOGRAFIA E ESTATÍSTICA Levantamento Sistemático da Produção Agrícola. Área plantada e produção de soja. Brasília-DF: IBGE, 2017. Disponível em: https://sidra.ibge.gov.br/home/lspa. Acesso em: 14 jan. 2017.
JAMES, C. Global Status of Commercialized Biotech/GM Crops. Ithaca-NY: ISAAA, 2014. 23 p.

MARTIN, N. B.; SERRA, R.; OLIVEIRA, M. D. M.; ÂNGELO, J. A.; OKAWA, H. Sistema integrado de custos agropecuários - CUSTAGRI. Informações Econômicas, São Paulo-SP, v. 28, n. 1, p.7-28, 1998.

MATSUNAGA, M.; BEMELMANS, P. F.; TOLEDO, P. E. N.; DULlEY, R. D.; OKAWA, H.; PEDROSO, I. A. Metodologia de custos de produção utilizada pelo IEA. Agricultura em São Paulo, São Paulo-SP, v. 23, n. 1, p. 123139,1976

MELO, R. S. S.; SILVA, A. S.; SILVA, I. F.; SOUZA, M. A.; SILVA NETO, L. F. Sistemas de culturas com milho sob semeadura direta na região Nordeste do Brasil. Ciência Rural, Santa Maria-RS, v. 43, n. 9, p. 1535-1541, 2013.

MELO JÚNIOR, H. B.; CAMARGO, R.; WENDLING, B. Sistema de plantio direto na conservação do solo e água e recuperação de áreas degradadas. Enciclopédia Biosfera, Goiânia-GO, v. 07, n. 12, p. 1-17, 2011.

MENEGATTI, A. L. A; BARROS, A. L. M. Análise comparativa dos custos de produção entre soja transgênica e convencional: um estudo de caso para o Estado do Mato Grosso do Sul. Revista de Economia e Sociologia Rural, Brasília-DF, v. 45, n. 1, p. 163-183, 2007.

OLIVEIRA, C. M.; SANTANA, A. C.; HOMMA, A. K. Os custos de produção e a rentabilidade da soja nos municípios de Santarém e Belterra, estado do Pará. Acta Amazônica, Manaus-AM, v. 43, n. 01, p. 23-32, 2013.

RICHETTI, A. Estimativa do custo de produção de algodão, safra 2007/08, para Mato Grosso do Sul e Mato Grosso. Dourados-MS: Embrapa Agropecuária Oeste, 2007. 14 p. (Comunicado Técnico, 136).

RICHETTI, A. Viabilidade econômica da cultura da soja na safra 2012/2013, em Mato Grosso do Sul. Dourados-MS: Embrapa Agropecuária Oeste, 2012. 9 p. (Comunicado Técnico, 177).

RICHETTI, A. Viabilidade econômica da cultura da soja na safra 2015/2016, em Mato Grosso do Sul. Dourados-MS: Embrapa Agropecuária Oeste, 2015. 13 p. (Comunicado Técnico, 202).

SILVA, A S.; SOUZA, L. C. F. Análise econômica de sucessões de culturas para milho, com níveis de nitrogênio em cobertura. Revista Brasileira de Milho e Sorgo, Sete LagoasMG, v. 6, n. 2, p. 256-262, 2007.

SIQUEIRA NETO, M.; VENZKE FILHO, S. P.; PICCOLO, M. C.; CERRI, C. E. P.; CERRI, C. C. Rotação de culturas no sistema plantio direto em Tibagi (PR). I - Sequestro de carbono no solo. Revista Brasileira de Ciência Solo, ViçosaMG, v. 33, n. 4, p. 1013-1022, 2009.

VILELA, R.; ARF, M.; TOMQUELSKI, G.; DIAS, A.; ANSELMO, J.; BERNART, L.; Estimativa do custo de produção do cultivo de soja na região dos chapadões - ano agrícola 2015/16. Pesquisa, Tecnologia e Produtividade, Chapadão do Sul-MS, v. 1, n. 9, p. 208-212, 2016. 